\title{
RETIREMENT OF DR LINDA NASH, EXECUTIVE EDITOR
}

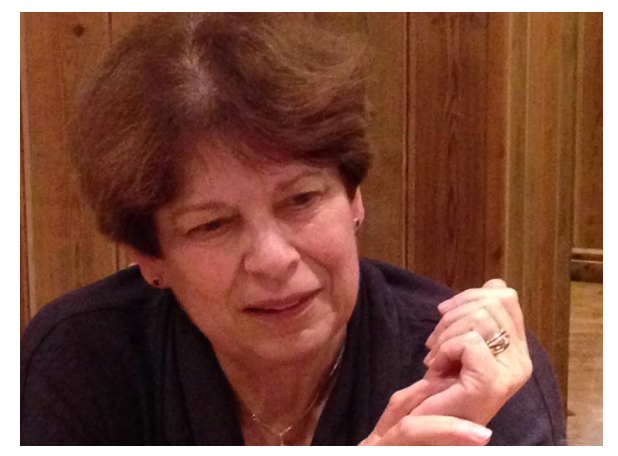

Linda Nash

We were fortunate that Dr Linda Nash took over the duties of Executive Editor of the Applied Probability Trust journals when Mavis Hitchcock retired in 1992. She brought her many talents to the job, and has ensured that the Trust continues to flourish in these difficult times for the publishing industry. Correspondence with authors, referees and the Editor-in-Chief as well as administrating the journal files has accounted for the bulk of her time, and here she has shown meticulous care in the administrative aspects as well as a great sense of diplomacy when communicating with sometimes disappointed and difficult authors. In addition, she has had the continued oversight of the office at large, including management of the financial activities of the APT, and the varied occasional activities that can be time consuming.

Many of these activities have been part of the electronic revolution. Electronic correspondence and record keeping have become the norm, and installing a suitable system was one of several 'odd jobs' to be undertaken. In the late 90s Linda facilitated the APT joining many mathematics and science-based organisations having their back issues of journals electronically digitized through the Carnegie-Mellon JSTOR initiative. Similarly, current and recent issues of JAP and AAP are now available through the mathematics and statistics project EUCLID.

In recent times there have been annual Applied Probability Trust lectures at The University of Sheffield, fostered by Linda; written versions of some of these lectures have subsequently been published in JAP.

Linda has maintained excellent relations with the School of Mathematics and Statistics at The University of Sheffield, as witness their hosting a retirement reception where the School through David Applebaum, the Trust through Daryl Daley, and JAP/AAP through the Editor-in-Chief Søren Asmussen, made presentations to Linda, each with tributes to her dedication and success. Linda is being succeeded by Dr Emma Talib who has been the APT Production Editor since 2007, but will continue to be available as a consultant to the Trust.

Linda is a keen opera fan, and maintains with husband Bruce Collins a fine garden at their retreat in Scarborough on the Yorkshire coast. We wish her a very happy retirement.

J. GANI

S. ASMUSSEN

D. DALEY 